\title{
Correlation of the expression of heparanase and heparin-binding EGF-like growth factor in the implantation window of nonconceptual cycle endometrium
}

\author{
Przemyslaw Wirstlein, Mateusz Mikolajczyk, Jana Skrzypczak
}

Department of Gynecology and Obstetrics, Division of Reproduction, University of Medical Sciences, Poznan, Poland

\begin{abstract}
Although it was suggested that heparanase (HPSE) may affect implantation and pregnancy, so far there have been no wide-ranging studies on the expression of and possible disturbances in the interactions between HPSE, heparan sulfate (HS) and related growth factors, such as heparin-binding EGF-like growth factor (HB-EGF). The aim of this study was to evaluate whether the expression profile of both HPSE and HB-EGF can be associated with impaired reproduction in the endometrial implantation window, in the non-conception cycle. The study group consisted of 32 women with two or more unexplained, consecutive miscarriages, and 61 idiopathic infertility patients, while the control comprised of 22 women with normal reproductive potential. We compared the expression of HB-EGF and HPSE at the transcript (qPCR) and protein (Western Blot) levels in eutopic endometrium. Also assessed were correlations between both factors in the studied groups. In women with consecutive miscarriages we observed lower HPSE relative transcript $(p=0.003)$ and lower protein $(p=0.002)$ level compared with the control group. Level of the HB-EGF protein was decreased $(p=0.017)$. HPSE mRNA level was higher in idiopathic infertility $(p=0.003)$ compared with women with miscarriages. We found statistically significant correlations in both transcript and protein levels in all groups $(\mathrm{p}<0.05)$. Our results allow the assumption of the existence of a process by which, in normal human endometrium, HB-EGF expression coincides with the synthesis of HPSE. As a result, the HB-EGF molecule can bind to the HS on the cell surface, enhancing its affinity to the receptor. Then, the release of growth factors associated with HS oligomers occurs that is catalyzed by HPSE. We suggest that one of the causes of unexplained miscarriages may result from the impaired expression of HPSE and HB-EGF. (Folia Histochemica et Cytobiologica 2013, Vol. 51, No. 2, 127-134)
\end{abstract}

Key words: heparanase, HB-EGF, recurrent miscarriage, idiopathic infertility, implantation

\section{Introduction}

Implantation of the embryo is a key moment for the further development of the pregnancy. For this to happen, both the embryo and the mother must be properly prepared. The ability of the endometrium to accept the embryo occurs 7-9 days after ovulation and is manifested by a series of morphological and biochemical features, which are referred to collectively as endometrial recep-

Correspondence address: P. Wirstlein, Department of Gynecology and Obstetrics, Division of Reproduction, University of Medical Sciences in Poznan, Polna St. 33, 60-535 Poznan, Poland; tel.: +48 6184193 02, fax: +48 618419625 ;

e-mail: abys@wp.pl tivity [1]. Despite the many potential factors responsible for the success of the implantation, it still remains the period of pregnancy that has the highest risk of failure. Only $50-60 \%$ of the embryos develop past 20 weeks of gestation. It is estimated that $75 \%$ of blastocysts are not implanted in the endometrium, remaining clinically unrecognized pregnancies [2-4].

The study of implantation in animal models, in relation to humans, may be subject to erroneous conclusions. This is due to the specific biochemical and physiological differences in implantation that are specific for mammalian species. It is a fact that the common and necessary step for implantation is the direct contact of the blastocyst with the endothelial lining of the uterus - the receptive endometrium [5]. 
From a clinical perspective it is important to find factors that can be used to determine the maturity of endometrial and/or the chances of successful pregnancy in patients with impaired reproduction. Among the candidates for biochemical markers are adhesion molecules: $\alpha \mathrm{V} \beta 3$ integrin, E-cadherin and glycocalyx glycosaminoglycans [6-9]. It should also be noted that the embryo is an entity allogenic to the mother, and the success of implantation, and in consequence pregnancy, depends on the immune status of the endometrial environment. Therefore, many researchers believe that the cause of failure of pregnancies lies in the mother's immunological profile, characterized by cytokines and certain subpopulations of lymphocytes [10].

Implantation and trophoblast invasion is also associated with changes in the tissue structure. The building blocks of the extracellular matrix (ECM), together with the ECM-degrading enzymes, are responsible for this process. The ECM not only maintains the tissue structure, but is also responsible for its receptivity, remodeling, angiogenesis and the creation of connections between the trophoblast and decidua [11].

An important component of ECM is heparan sulfate (HS). Its presence has been demonstrated in the endometrium, the decidua and the trophoblast invasion area [12]. HS not only acts as an integrating molecule by binding tissues and cells. It is also a binding and release site for angiogenic growth factors such as heparin-binding EGF-like growth factor (HB-EGF), vascular epithelial growth factor (VEGF) and fibroblast growth factor family (FGF's), as well as bone morphogenetic proteins (BMP's). Binding of these factors with HS as a co-receptor not only increases their concentration, but also modulates their effects on target cells $[13,14]$. On the other hand, ECM stimulates angiogenesis and growth of the trophoblast by releasing factor-HS complex [15].

Heparanase or endo- $\beta$-D-glucuronidase (HPSE) is responsible for HS degradation, cell migration and release of heparan sulfate binding agents, which divides the sugar chains at specific sites, generating short oligosaccharides, consisting of 10-20 sugar residues [16]. HPSE, a factor influencing vascularization and growth, has been extensively studied in the process of carcinogenesis. HPSE is expressed in human tumors. Its over-expression confers an accelerated growth and invasive phenotype in experimental animals. In contrast, HPSE gene silencing is associated with a marked inhibition of tumor progression. Heparanase upregulation correlates with increased tumor vascularity and poor postoperative survival of cancer patients [17]. Oncological studies demonstrated not only the enzymatic, but also non-enzymatic, angiogenic acti- vity of HPSE [18]. Additionally, it has to been noted that the reduction in the expression of HPSE in vitro impairs, in a non-enzymatic way, angiogenesis and hemostasis by reducing the expression of VEGF and tissue factor (TF) [19].

It is not known whether an analogous situation occurs in the endometrium. There has been relatively little research on the role of HPSE expression and the processes related to endometrial receptivity and implantation. In mammals, including primates and humans, expression of HPSE has been found in endometrium and placenta, whereas a murine model has demonstrated its key role in the process of implantation [20-26].

Studies on mouse blastocyst implantation have shown that the synthesis of HB-EGF is closely associated with the implantation site. In a mouse endometrium HB-EGF is produced in the form of a protein associated with endometrial epithelium that binds to HS present on the surface of the blastocyst, and, as demonstrated in vitro, endometrial HB-EGF acts as the blastocyst growth factor through the receptors for epidermal growth factors (EGF) - HER1 and HER4 [27, 28].

Although it has been suggested that HPSE affects implantation and pregnancy, so far there have not been any wide-ranging studies on the expression of and possible disturbances in the interactions between HPSE, HS and related growth factors (such as HB-EGF) in implantation in women with impaired reproduction.

In this investigation we tried to assess the expression of both HPSE and HB-EGF. We aimed to answer the question as to whether the expression profile of both markers may be associated with impaired reproduction in the endometrial implantation window, in the non-conception cycle.

\section{Material and methods}

Patients and controls. The study, which was approved by Karol Marcinkowski Medical University bioethical committee, included 115 reproductive-age women. The study group consisted of 32 women with two or more unexplained, consecutive miscarriages, 61 idiopathic infertility patients and the control group comprised of 22 women with normal reproductive potential. The women in the miscarriage group have had at least two consecutive unexplained miscarriages in the first trimester of pregnancy. This group included 20 women with diagnosed recurrent miscarriage (e.g. 3 consecutive miscarriages). The mean duration of infertility in idiopathic infertility patients was 3 years (range: $1-5$ years). The control group consisted of women that had at least one child, regular menses, and were without anatomical or functional changes within the endometrium. Those patients 
Table 1. Clinical characterization of the studied groups.

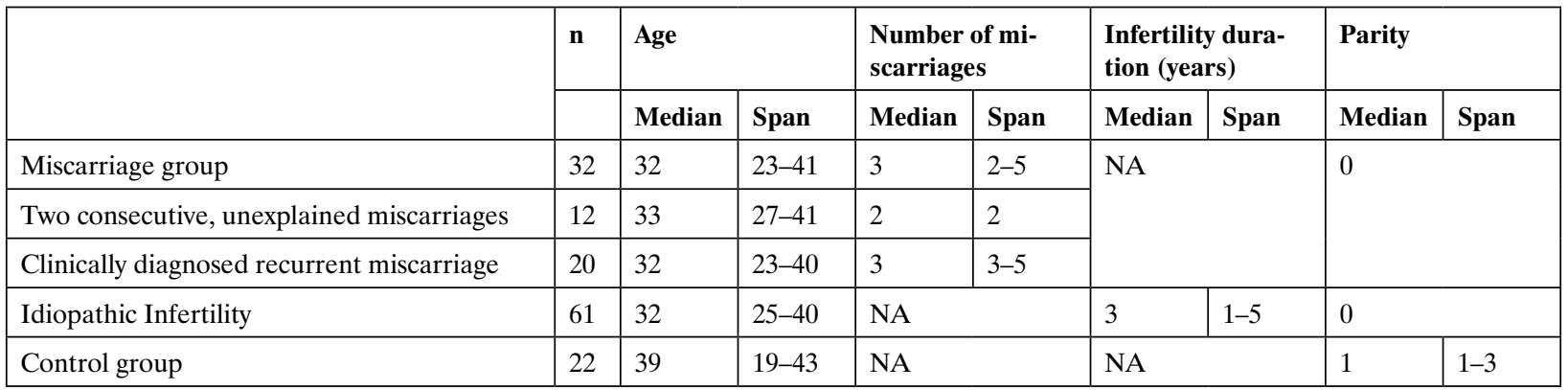

were asked to donate their endometrium for the investigation. The study protocol was approved by the local ethical committee, and the patients signed an informed consent form. No patients in the study or control group had taken any hormonal preparations for at least three months prior to the study. The exclusion criteria were: current use of hormonal contraception, any serious diseases. The age of women, number of miscarriages and parity are presented in Table 1.

Sample collection. In each woman endometrium samples was scraped from uterine wall. A pipelle or hysteroscopic biopsy was used to acquire samples during the implantation window, which occurred 7-9 days after ultrasound confirmed ovulation. Part of the each sample was taken for histological assessment, according to the Noyes and Hertig criteria [29]. The reminder of the endometrial sample for qPCR and Western blot was placed overnight in Allprotect Tissue Reagent solution (Qiagen GmbH, Hilden, Germany) and next frozen in liquid nitrogen until extraction.

RNA isolation and protein extraction. Both fractions were conducted with the use of an AllPrep DNA/RNA/Protein Mini Kit (Qiagen). For the total RNA isolation we used, due to the manufacturer recommendation an additional RNase-Free DNase Set (Qiagen) to eliminate the risk of DNA contamination.

Reverse transcription and qPCR. The quantity at OD 260 $\mathrm{nm}$ and purity at OD 260/280 nm of the total RNA samples was checked spectrophotometrically with a NanoDrop ND1000 (Thermo Scientific, USA), after RNA isolation. To acquire cDNA, the $1 \mu \mathrm{g}$ RNA was treated with QuantiTect Reverse Transcription (Qiagen). Up to $30 \mathrm{ng}$ resulting cDNA was used as a matrix for qPCR.

The expression of the studied transcripts was established according to a housekeeping gene, namely the human large ribosomal protein (RPLP0). Specific primers for HPSE and HB-EGF in qPCR technique were created with Primer3 software [30] based on an mRNA sequence from the NCBI Gene database [31]. Primers for RPLP0 were designed on the basis of the RTPrimerDB [32]. The specificity of the constructed primer was checked against the BLAST database [33]. The specificity and length of these products was also confirmed on agarose. The following primers were used: for HPSE forward: 5'-ATCAATGGGTCGCAGTTAGG - 3' and reverse: 5' AGGCTGACCATCAGGAC - 3', for HB-EGF - forward: 5' - TGAGGTGGGTGGGATTATACA - 3' and reverse: 5'TTGGAGCTGACTGTTCTTGGT3', and for RPLP0 forward: 5' - GGCGACCTGGAAGTCCAACT - 3' and reverse 5' - CCATCAGCACCACAGCCTTC - 3'.

All reactions were conducted using a DyNAmo HS SYBR Green qPCR Kit (Finnzymes, Finland) and a RotorGene 3000 thermocycler (Corbett Research, Australia). The specificity of the achieved reaction products was assessed in $2 \%$ agarose gel and a second derivative of the melting curve for the PCR reaction. The thermal profile was based on the manufacturer's instructions regarding the specific annealing temperature of the primers. To establish the levels of the given transcripts in the studied samples, we constructed standard curves generated by the $\mathrm{Ct}$ (the value where the amplification curve crosses the threshold line) with six subsequent ten-fold dilutions of linear DNA, which was the PCR product of a given set of primers. For each sample, duplicated qPCR was processed in the presence of positive controls and no template control. The HPSE, HB-EGF and RPL0 mRNA levels were expressed as the ratio of studied and reference cDNA amount.

Western blot analysis. Previously obtained sample extracts, containing $30 \mu \mathrm{g}$ of protein samples, were separated by electrophoresis in a 4-12\% SDS-polyacrylamide gel (Bis-Tris NuPAGE, Invitrogen, USA). The separated proteins were transferred to a PVDF membrane and blocked with TBST (TBS plus $0.1 \%$ Tween-20) containing $4 \%$ BSA. Immunodetection was processed with the use of rabbit polyclonal antibody anti-HPSE (H-80, $200 \mu \mathrm{g} / \mathrm{mL})$ and rabbit polyclonal antibody anti-HB-EGF (H-88; $200 \mu \mathrm{g} / \mathrm{mL}$, Santa Cruz Biotechnology, Dallas, TX, USA) at 1:200 concentrations. For ACTB detection, rabbit polyclonal anti-ACTB antibody was used at a 1:400 concentration $(\mathrm{N}-21 ; 100 \mu \mathrm{g} / \mathrm{mL}$, Santa Cruz). Goat anti-rabbit, conjugated with Alexa Fluor 663 (Invitrogen, USA), was used as the secondary antibody. Bands were revealed using a Fuji FLA5100 Fluorescent Image Analyser (FujiFilm, Japan) scanner. The quantities 
Table 2. Relative transcript and protein level of HPSE or HB - EGF in endometrium from women with two or more consecutive miscarriages, idiopathic infertility and the control group

\begin{tabular}{|c|c|c|c|c|c|c|c|}
\hline \multirow{2}{*}{\multicolumn{2}{|c|}{ Gene }} & \multicolumn{2}{|l|}{$\begin{array}{l}\text { Controls } \\
\mathrm{n}=\mathbf{2 2}\end{array}$} & \multicolumn{2}{|c|}{$\begin{array}{l}\text { Two or more consecutive miscar- } \\
\text { riages } n=32\end{array}$} & \multicolumn{2}{|c|}{ Idiopathic infertility $n=61$} \\
\hline & & $\begin{array}{l}\text { Median } \\
\text { (span) }\end{array}$ & $\begin{array}{l}\text { Mean } \\
( \pm \text { SD })\end{array}$ & $\begin{array}{l}\text { Median } \\
\text { (span) }\end{array}$ & $\begin{array}{l}\text { Mean } \\
( \pm \text { SD })\end{array}$ & $\begin{array}{l}\text { Median } \\
\text { (span) }\end{array}$ & $\begin{array}{l}\text { Mean } \\
( \pm \text { SD })\end{array}$ \\
\hline \multirow[t]{2}{*}{ HPSE } & Transcript $^{\mathrm{a}}$ & $\begin{array}{l}0.056 \\
\left(2.95 \mathrm{E}^{-3}-0.153\right)\end{array}$ & $\begin{array}{l}0.068 \\
( \pm 0.007)\end{array}$ & $\begin{array}{l}0.011 \\
\left(5.17 \mathrm{E}^{-4}-0,312\right)^{*} \dagger\end{array}$ & $\begin{array}{l}0.045 \\
( \pm 0.015)\end{array}$ & $\begin{array}{l}0.04 \\
\left(4.87 \mathrm{E}^{-4}-0.797\right) \dagger\end{array}$ & $\begin{array}{l}0.107 \\
( \pm 0.022)\end{array}$ \\
\hline & Protein $^{\mathrm{b}}$ & $\begin{array}{l}0.565 \\
(0.006-1.173)\end{array}$ & $\begin{array}{l}0.525 \\
( \pm 0.421)\end{array}$ & $\begin{array}{l}0.01 \\
(0.005-0.821)^{*}\end{array}$ & $\begin{array}{l}0.077 \\
( \pm 0.211)\end{array}$ & $\begin{array}{l}0.017 \\
(0.005-1.091)\end{array}$ & $\begin{array}{l}0.296 \\
( \pm 0.395)\end{array}$ \\
\hline \multirow[t]{2}{*}{$\begin{array}{l}\text { HB } \\
\text {-EGF }\end{array}$} & Transcript $^{\mathrm{a}}$ & $\begin{array}{l}0.0113 \\
\left(1.5 \mathrm{E}^{-3}-0.0484\right)\end{array}$ & $\begin{array}{l}0.014 \\
( \pm 0.012)\end{array}$ & $\begin{array}{l}0.009 \\
\left(1.0 \mathrm{E}^{-3}-0.124\right)\end{array}$ & $\begin{array}{l}0.016 \\
( \pm 0.021)\end{array}$ & $\begin{array}{l}0.007 \\
\left(5.24 \mathrm{E}^{-4}-0.115\right)\end{array}$ & $\begin{array}{l}0.011 \\
( \pm 0.016)\end{array}$ \\
\hline & Protein ${ }^{b}$ & $\begin{array}{l}0.641 \\
(0.052-3.6962)\end{array}$ & $\begin{array}{l}1.028 \\
( \pm 0.223)\end{array}$ & $\begin{array}{l}0.015 \\
(0.01-1188)^{* *}\end{array}$ & $\begin{array}{l}0.4 \\
( \pm 0.407)\end{array}$ & $\begin{array}{l}0.404 \\
(0.010-1.367)\end{array}$ & $\begin{array}{l}0.487 \\
( \pm 0.411)\end{array}$ \\
\hline
\end{tabular}

${ }^{a}$ The amount of cDNA corresponding to HPSG and HB-EGF transcripts, were normalized to RPL0 housekeeping gene transcript; ${ }^{\text {b The amount }}$ of Western blot-detected proteins was presented as the HPSE or HB-EGF to ACTB protein band fluorescent signal ratio. P values for studied groups vs. controls were assessed by ANOVA on Ranks with Multiple Comparisons versus Control Group (Dunn's Method). *p < 0.005; $* * \mathrm{p}<0.05 ; \dagger \mathrm{p}<0.005$

of Western blot-detected HPSE and HB-EGF and ACTB proteins were determined based on the fluorometry. The band fluorometry readings were normalized to the ACTB loading control to calculate the studied protein to ACTB fluorescent signal ratio.

Statistical analysis. For statistical analysis, SigmaStat 3.5 software was used (Systat Software, Inc., USA). The analysis of the results was based on Kruskal-Wallis one-way ANOVA on Ranks with Multiple Comparisons versus Control Group (Dunn's Method) and the Spearman Rank Correlation Test; $\mathrm{p}<0.05$ was considered statistically significant.

\section{Results}

We used qPCR and Western blot analysis to evaluate HPSE and HB-EGF transcript and protein levels in the endometrium samples of women with two or more unexplained miscarriages, idiopathic infertility patients and the controls. In women with consecutive miscarriages, we observed lower HPSE relative transcript level $(\mathrm{p}=0.003)$ and lower protein level $(p=0.002)$ compared to controls. The level of HB-EGF proteins was lower $(\mathrm{p}=0.017)$ but the level of the HB-EGF transcript, despite the fact that it was lower, was not statistically different when compared with the controls (trend $\mathrm{p}<0.164$ ).

Expression of the studied genes, despite being lower, was not significantly different in women with idiopathic infertility compared with the controls. Also, we have not observed any statistically significant differences between women with miscarriages and infertile women, with the exception of the HPSE mRNA level, which was higher in idiopathic infertility $(\mathrm{p}=0.003)$ (Table 2$)$.
We also compared correlations between HPSE and HB-EGF levels in all the studied groups. We found statistically significant correlations both in transcript and protein levels in all groups $(\mathrm{p}<0.05)$ (Figure 1).

\section{Discussion}

HPSE in the endometrium, in both mice and humans, changes the glycocalyx structure, and removes HS facilitating mutual contact between the embryo and the decidua. However, in the process of implantation, it seems more appropriate to view the HPSE as an adhesive agent and/or a protein transcription factor [34]. In turn, an in vivo mouse model, and later also in primates, a multiple increase in HPSE enzyme activity was demonstrated during pregnancy. This phenomenon was not accompanied by increased expression of HPSE in relation to the expression of this protein in the endometrium during the implantation window. A similar phenomenon was also observed in the human decasualization of the endometrium in vitro $[35,36]$. These observations, regarding the level of the HPSE protein and its activity in the endometrium and decidua in mammals, indicate a biochemical mechanism that switches the function of HPSE from an adhesion molecule and/or signaling functional hydrolase. During the implantation window HPSE would assist embryo implantation, and during pregnancy HPSE acts as an angiogenesis-stimulating factor, and mostly as a catalyst in the ECM changes. One of the mechanisms that controls the activity of HPSE may be a change in $\mathrm{pH}$. It has been shown that the catalytic activity 
Transcripts HPA1 and HB-EGF correlations, assesed by Spearman Rank Order Correlation
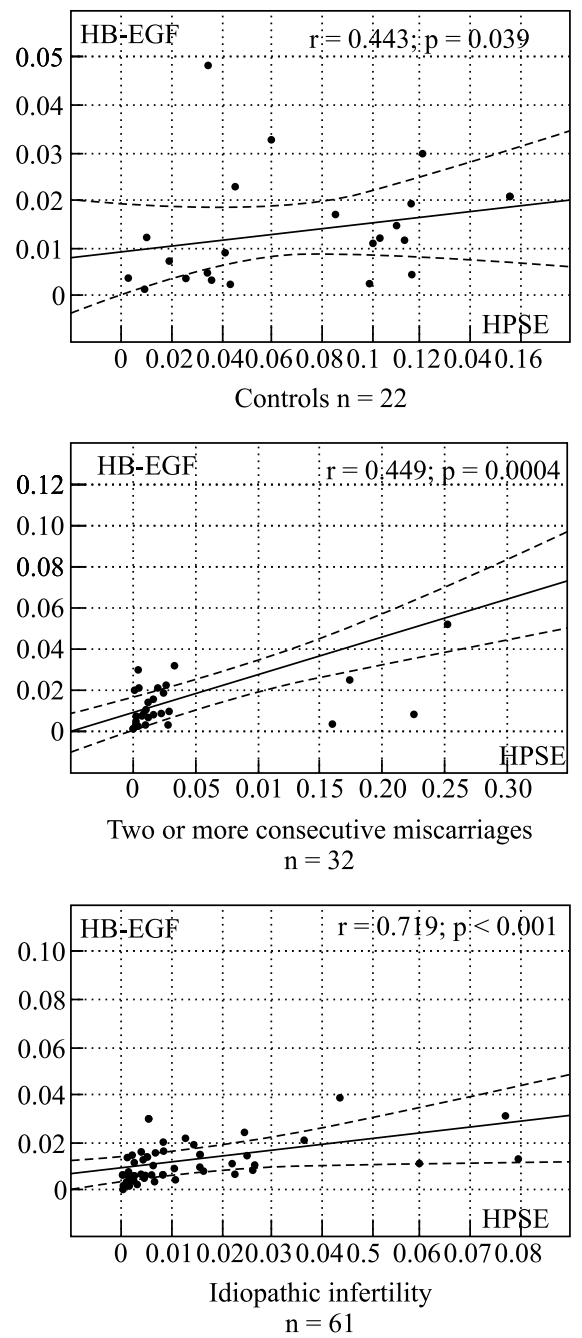

Protein levels HPS1 and HB-EGF correlations, assesed by Spearman Rank Order Correlation
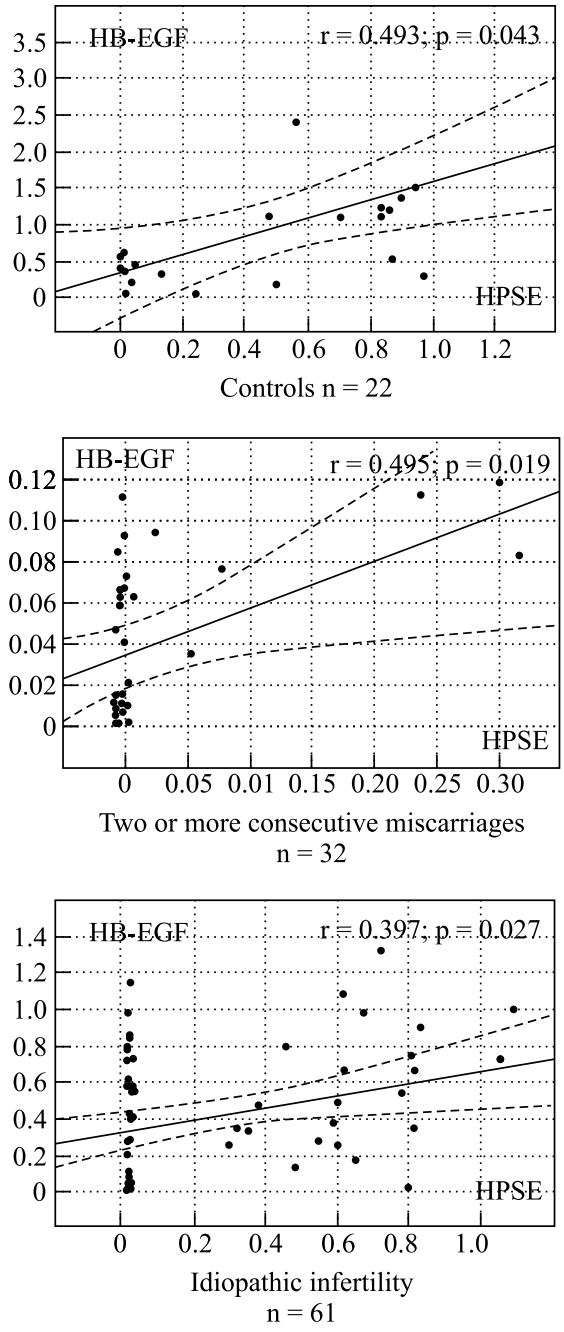

Figure 1. HPSE and HB-EGF correlation, assessed by Spearman Rank Order Correlation. The correlation coefficients value and p-value were depicted in upper-right corners. Dashed lines define the $95 \%$ confidence interval

of HPSE reaches a maximum at $\mathrm{pH} 5.0$, while the $\mathrm{pH}$ during the menstrual cycle in the uterine cavity varies between 6.6 and 7.6. This $\mathrm{pH}$ favors the adhesive properties of HPSE, even in the form of a proenzyme that is catalytically inactive [37-39].

In our study, the expression of HPSE in women with two or more abortions was significantly lower compared with the control group. Also, it the same group, the transcript level of HPSE was lower compared with infertile women; whereas HPSE protein levels in infertile women did not differ compared with the control group. Taking this into account, one can assume that in the decidua in the early stages of pregnancy HPSE - by its proangiogenic activity - is responsible for the maintenance of pregnancy and trophoblast invasion. On the other hand, it is responsible, to a lesser extent, for the direct binding of the embryo to the endometrium, thus initiating the implantation.

Nadir et al. [40], showed that in placental biopsies derived from women with recurrent miscarriage and thrombophilia expression level of HPSE was higher in relation to the results obtained from placentas, from women without a negative obstetric history. However, in histological material derived from women with thrombophilia and recurrent fetal loss and also in the controls stronger HPSE expression was observed in placental fragments of fetal origin compared to fragments of maternal origin [40]. Perhaps the cause of early pregnancy loss could be traced back to the imbalanced expression of HPSE and its control mechanisms and its activation in the placenta. The same authors also pointed to the thrombotic activity of HPSE [41]. 
We both evaluated the transcript as well as the level of the HB-EGF protein. In women with two or more consecutive pregnancy losses we have observed lower, but statistically not significant levels of the HB -EGF transcript confirming our earlier studies [42]. Thus, the results of the expression of both HB-EGF and HPSE seem to suggest an important role of these proteins in the development of the placenta.

In contrast to the mouse, HB-EGF in human endometrium is also synthesized in the stroma (at the mRNA level, throughout the whole cycle), the decidua and the chorion [43]. The correlation of increased synthesis of HB-EGF and EGFR receptors in the stroma suggests that in the human endometrium HB-EGF has a more complex role than that found in mice. It is postulated that in the human endometrium HB-EGF acts as a factor responsible for the maturation of the endometrium and decasualization, via possible regulation of apoptosis in stromal cells. In addition, HB-EGF has been shown to have increased affinity for the EGFR when it is associated with HS [44]. HB-EGF stimulates the expression of those factors limiting the activation of the complement. The ability of HB-EGF to stimulate tumor invasion was demonstrated by many authors [45-48]. Similarly, as in the case of HPSE, it can be assumed that HB-EGF promotes not only implantation, but also plays an important role in trophoblast invasion. These findings should explain the beneficial effects of low molecular weight heparin (LMWH) on the maintenance of pregnancy. We can assume that LMWH works as an antithrombotic agent, and thus antagonizes the aforementioned thrombotic action of HPSE, as described by Nadir et al. [40]. However, the protective effect of LMWH during pregnancy stands in opposition to the observed its anti-neoplastic effect [49]. Moreover, LMWH has an antiapoptotic effect and stimulates the expression of HB-EGF in decidual cells in vitro [50].

It has been independently shown that the expression of both HPSE and HB-EGF in the endometrium is stimulated by sex hormones [51, 52]. Both factors are important for implantation and their roles seem to be complementary.

We found positive correlation between expression of the HPSE and HB-EGF in the control, and both studied groups. There was a strong correlation of the transcripts of HPSE and HB-EGF in the group of women with primary infertility. On the one hand, this is probably the effect of group size. It is almost three times greater than the control group and almost two times greater than the group of women with consecutive miscarriages. On the other hand, we did not found strong correlation between the expressions at the protein level of both studied genes. The observed difference in correlations in the group of infertile women might bring us closer to explain the phenomenon of pre-clinical pregnancy loss. This phenomenon is on the borderline between primary infertility and recurrent miscarriages. There, miscarriage can occur shortly after implantation and because it is similar to menstrual bleeding it does not to arouse suspicion of women [53, 54].

Our findings may be also explained as post-transcriptional expression disorder. Both HPSE and HB-EGF proteins are secreted out into the ECM, and are subject to post-translational processing. We cannot exclude that in some infertile women there is a defect that disturbs the mRNA signal sequences, controlling the translation or post-translational processing. Such a phenomenon has been postulated in the impaired expression of protamine in the process of spermatogenesis [55]. Based on this assumption, no statistically significant differences in the level of expression of the studied proteins in relation to the control group can be explained by the action of the compensatory mechanisms in the endometrium in infertile women .

However, the observed correlation between the expression of HPSE and HB-EGF allows the assumption of the existence of a process by which, in normal human endometrium, HB-EGF expression stimulated by estradiol (E2) and progesterone (P4) coincides with the synthesis of HPSE controlled by E2. As a result, the HB-EGF molecule binds to the HS on the cell surface, enhancing its affinity to the EGF receptor. Then, there occurs the release of growth factors associated with HS oligomers which is catalyzed by HPSE. Despite reports indicating that HPSE is a factor affecting implantation and pregnancy development [36, 37], there are no detailed studies on the expression of and possible disturbances in the interactions between HPSE system, HS and growth factors involved in implantation in women with impaired reproduction. This engenders another potential area of research because, due to their characteristics, HPSE and factors associated with HS should be considered as important parameters of endometrial receptivity, in both a direct and indirect way.

\section{Acknowledgment}

This study was supported by the Ministry of Science and Higher Education, grant 2011/01/B/ /NZ5/02788.

\section{References}

1. Yoshinaga K. Uterine receptivity for blastocyst implantation. Ann NY Acad Sci. 1988;541:424-431.

2. Guzeloglu-Kayisli O, Basar M, Arici A. Basic aspects of implantation Reprod Biomed Online. 2007;15:728-739. 
3. Zinaman MJ, Clegg ED, Brown CC, O’Connor J, Selevan SG. Estimates of humanfertility and pregnancy loss. Fertil Steril. 1996;3:503-509.

4. Wilcox AJ, Weinberg CR, O'Connor JF et al. Incidence of early loss of pregnancy. $N$ Engl J Med. 1988;4:189-194.

5. Sharkey AM, Smith SK. The endometrium as a cause of implantation failure. Best Pract Res Clin Obstet Gynaecol. 2003;2:289-307.

6. Apparao KB, Murray MJ, Fritz MA et al. Osteopontin and its receptor $\alpha \mathrm{V} \beta 3$ integrin are coexpressed in the human endometrium during the menstrual cycle but regulated differentially. J Clin Endocrinol Metab. 2001;10: 4991-5000.

7. Halbersztadt A, Pajak J, Nowicki P et al. Implantation and antigenicity of human endometrium. Postepy Hig Med Dosw. 2006;60:71-77.

8. San Martin S, Soto-Suazo M, Zorn TM. Perlecan and syndecan-4 in uterine tissues during the early pregnancy in mice. Am J Reprod Immunol. 2004; 1:53-59.

9. Germeyer A, Klinkert MS, Huppertz AG et al. Expression of syndecans, cell-cell interaction regulating heparan sulfate proteoglycans, within the human endometrium and their regulation throughout the menstrual cycle. Fertil Steril. 2007; 3:657-663.

10. Koot YE, Teklenburg G, Salker MS, Brosens JJ, Macklon NS. Molecular aspects of implantation failure. Biochim Biophys Acta. 2012;2:1943-1950.

11. Gaide Chevronnay HP, Selvais C, Emonard H, Galant C, Marbaix E, Henriet P. Regulation of matrix metalloproteinases activity studied in human endometrium as a paradigm of cyclic tissue breakdown and regeneration. Biochim Biophys Acta. 2012;1:146-156.

12. Dziadek M, Fujiwara S, Paulsson M, Timpl R. Immunological characterization of basement membrane types of heparin sulfate proteoglycan. EMBO J. 1985;4:905-912.

13. Kirn-Safran C, D’Souza S, Carson D. Heparan Sulfate Proteoglycans and Their Binding Proteins in Embryo Implantation and Placentation. Semin Cell Dev Biol. 2008;2:187-193.

14. Ashikada-Hada S, Habuchi H, Kariya Y, Itoh N, Reddi AH, Kimata K. Charakterization of growth factor-binding structures in heparin/heparin sulfate using an octasaccharide library. J Biol Chem. 2004;13:12346-12354.

15. MahalingamY, Gallagher JT, Couchman JR. Cellular adhesion responses to the heparin-binding (HepII) domainof fibronectin reqire heparin sulfate with specific properties. J Biol Chem. 2007;5:3221-3230.

16. Bame KJ. Heparanases: endoglycosidases that degrade heparin sulfate proteoglycans. Glycobiology. 2001;6:91R-98R.

17. Vlodavsky I, Ilan N, Nadir Y et al. Heparanase, heparin and the coagulation system in cancer progression. Thromb Res. 2007;120 Suppl 2:S112-122.

18. Elkin M, Ilan N, Ishai-Michaeli R et al. Heparanase as mediator of angiogenesis: mode of action. FASEB $J$. 2001;9:1661-1663.

19. Zetser A, Bashenko Y, Edovitsky E, Levy-Adam F, Vlodavsky I, Ilan N. Heparanase induces vascular endothelial growth factor expression: correlation with p38 phosphorylation levels and Src activation. Cancer Res. 2006;3:1455-1463.

20. Goshen R, Hochberg AA, Korner G et al. Purification and characterization of placental heparanase and its expression by cultured cytotrophoblasts. Mol HumReprod. 1996;9:679-684.

21. Dempsey LA, Plummer TB, Coombes SL, Platt JL. Heparanase expression in invasive trophoblasts and acute vascular damage. Glycobiology. 2000;5:467-475.
22. Kizaki K, Nakano H, Takahashi T, Imai K, Hashizume K. Expression of heparanase mRNA in bovine placenta during gestation. Reproduction. 2001;4:573-580.

23. Kizaki K, Yamada O, Nakano $\mathrm{H}$ et al. Cloning and localization of heparanase in bovine placenta. Placenta. 2003;4:424-430.

24. Hasengaowa, Kodama J, Kusumoto $\mathrm{T}$ et al. Heparanase expression in both normal endometrium and endometrial cancer. Int J Gynecol Cancer. 2006;3:1401-1406.

25. Xu X, Ding J, Rao G et al. Estradiol induces heparanase-1 expression and heparan sulphate proteoglycan degradation in human endometrium. Hum Reprod. 2007;4:927-937.

26. Zcharia E, Metzger S, Chajek-Shaul T et al. Transgenic expression of mammalian heparanase uncovers physiological functions of heparan sulfate in tissue morphogenesis, vascularization, and feeding behavior. FASEB J. 2004;2:252-263.

27. Raab G, Kover K, Paria BC, Dey SK, Ezzell RM, Klagsbrun M. Mouse preimplantation blastocysts adhere to cells expressing the transmembrane form of heparin-binding EGF-like growth factor. Development. 1996;2:637-645.

28. Paria BC, Elenius K, Klagsbrun M, Dey SK. Heparin-binding EGF-like growth factor interacts with mouse blastocysts independently of ErbB1: a possible role for heparan sulfate proteoglycans and ErbB4 in blastocyst implantation. Development. 1999;9:1997-2005.

29. Noyes RW, Hertig AT, Rock J: Dating the endometrial biopsy. Fertil Steril 1950;1: 3-25.

30. http://primer3.wi.mit.edu/ last acces 6 may 2013.

31. http://www.ncbi.nlm.nih.gov/gene last acces 6 may 2013.

32. http://medgen.ugent.be/rtprimerdb/ last acces 6 may 2013.

33. http://blast.ncbi.nlm.nih.gov/ last acces 6 may 2013.

34. Harris LK, Baker PN, Brenchley PE, Aplin JD. Trophoblast-derived heparanase is not required for invasion. Placenta. 2008;4:332-337.

35. D'Souza SS, Fazleabas AT, Banerjee P et al. Decidual heparanase activity is increased during pregnancy in the baboon (Papio anubis) and in in vitro decidualization of human stromal cells. Biol Reprod. 2008;2:316-323.

36. D'Souza SS, Daikoku T, Farach-Carson MC, Carson DD. Heparanase expression and function during early pregnancy in mice. Biol Reprod. 2007;3:433-441.

37. Revel A, Helman A, Koler M et al. Heparanase improves mouse embryo implantation. Fertil Steril. 2005;3:580-586.

38. Toyoshima M, Nakajima M. Human heparanase. Purification, characterization, cloning, and expression. J Biol Chem. 1999;274:24153-24160.

39. Gilat D, Hershkoviz R, Goldkorn I et al. Molecular behavior adapts to context: heparanase functions as an extracellular matrix-degrading enzyme or as a $\mathrm{T}$ cell adhesion molecule, depending on the local pH. J Exp Med. 1995;181:1929-1934.

40. Nadir Y, Henig I, Naroditzky I, Paz B, Vlodavsky I, Brenner B. Involvement of Heparanase in early pregnancy losses. Thromb Res. 2010;5:e251-257.

41. Nadir Y, Brenner B. Heparanase procoagulant effects and inhibition by heparins. Thromb Res. 2010;Suppl. 2:S72-76.

42. Wirstlein P, Mikolajczyk M, Skrzypczak J. Assessment of the transcription levels for the complement activation control system in eutopic endometrium in women with two or more consecutive miscarriages of unknown etiology. Folia Histochem Cytobiol. 2010;3:328-332.

43. Birdsall MA, Hopkisson JF, Grant KE, Barlow DH, Mardon HJ. Expression of heparin-binding epidermal growth factor messenger RNA in the human endometrium. Mol Hum Reprod. 1996;2:31-34. 
44. Chobotova K, Karpovich N, Carver J et al. Heparin-binding epidermal growth factor and its receptors mediate decidualization and potentiate survival of human endometrial stromal cells. J Clin Endocrinol Metab. 2005;2:913-919.

45. Yagi H., Yotsumoto F, Miyamoto S. Heparin-binding EGF -like growth factor promotes transcoelomic metastasis in ovarian cancer through epithelial-mesenchymal transition. Mol. Cancer Ther. 2008;7:3441-3451.

46. Tanaka Y, Miyamoto S, Suzuki SO et al. Clinical significance of heparin-binding EGF-like growth factor and a disintegrin and metalloprotease 17 expresion in human ovarian cancer. Clin Cancer Res. 2005;11:4783-4792.

47. Matsuzaki H, Kobayashi H, Yagyu T et al. Reduced syndecan-1 expression stimulates HB-EGF-mediated invasion in ovarian cancer cells in a urokinase-independent mechanism. Oncol Rep. 2005;14:449-457.

48. Miyamoto S, Hirata M, Yamazaki A et al. Heparin-binding EGF-like growth factor is a promising target for ovarian cancer therapy. Cancer Res. 2004;64:5720-5757.

49. Lazo-Langner A, Goss GD, Spaans JN and Rodger MA, The effect of low-molecular-weight heparin on cancer survival. A systematic review and meta-analysis of randomized trials. J Thromb Haemost. 2007;5:729-737.
50. Di Simone N, Di Nicuolo F, Castellani R et al. Low-molecular -weight heparins induce decidual heparin-binding epidermal growth factor-like growth factor expression and promote survival of decidual cells undergoing apoptosis. Fertil Steril. 2012;1:169-177.e1

51. Xu X, Ding J, Rao G et al. Estradiol induces heparanase-1 expression and heparan sulphate proteoglycan degradation in human endometrium. Hum Reprod. 2007;4:927-937.

52. Lessey BA, Gui Y, Apparao KB, Young SL, Mulholland. Regulated expression of heparin-binding EGF-like growth factor (HB-EGF) in the human endometrium: a potential paracrine role during implantation. J. Mol Reprod Dev. 2002;4:446-455.

53. Carrell DT, Emery BR, Hammoud S. Altered protamine expression and diminished spermatogenesis: what is the link? Hum Reprod Update. 2007;13:313-327.

54. Koot YE, Boomsma CM, Eijkemans MJ, Lentjes EG, Macklon NS. Recurrent pre-clinical pregnancy loss is unlikely to be a 'cause' of unexplained infertility. Hum Reprod. 2011;10:2636-2641.

55. Macklon NS, Geraedts JP, Fauser BC. Conception to ongoing pregnancy: the 'black box' of early pregnancy loss. Hum Reprod Update. 2002;8:333-343.

Submitted: 25 March, 2013 Accepted after reviews: 16 June, 2013 